\title{
Infecção pelo Parvovírus Canino no Rio de Janeiro: um estudo de cinco anos*
}

\section{Canine parvovirus infection in Rio de Janeiro: A five-year study}

\author{
Rita de Cássia N. Cubel Garcia, ${ }^{\star \star}$ José Paulo G. Leite, ${ }^{\star \star \star}$ Maria da Penha T. P. Xavier, ${ }^{\star \star}$ Liliane Maria V. Willi, ${ }^{\star \star \star \star}$ Mauro \\ Coelho Lemos, ${ }^{\star \star \star \star \star}$ Tatiana Xavier de Castro, ${ }^{\star \star \star \star \star}$ Regina Mertens, ${ }^{\star \star \star \star \star}$ Norma Vollmer Labarthe ${ }^{\star \star \star \star \star \star}$
}

\section{Resumo}

Amostras fecais de cães com até seis meses de idade, com gastrenterite, foram testadas para a presença do parvovírus canino (CPV) pelo teste de hemaglutinação (HA) e confirmadas como positivas pelo teste de inibição da hemaglutinação. Noventa e duas das 208 amostras recebidas no período de abril de 1995 a novembro de 2000 foram positivas. Aproximadamente, $76 \%$ das amostras foram obtidas de cães entre dois e quatro meses de idade. Entre os 92 animais positivos para CPV2,28 tinham sido vacinados, e para 11 destes o resultado positivo do HA poderia ser devido a detecção do vírus vacinal. Através da reação em cadeia pela polimerase, pode-se confirmar a infecção pelo virus selvagem em nove dos 11 animais vacinados. Neste estudo não foi possivel observar que fatores como sexo ou raça possam ser importantes no desenvolvimento da doença: No periodo estudado, o parvovírus canino pode ser detectado, em todos os meses do ano, não apresentando sazonalidade definida.

Palavras-chave: Parvovírus canino; gastrenterite; Rio de Janeiro.

\begin{abstract}
Fecal samples from puppies less than 7 months old with gastroenteritis were examined for canine parvovirus infection (CPV2) by hemagglutination test (HA) and confirmed as positive by hemagglutination-inhibition test. Ninety-two from 208 samples collected between April 1995 to November 2000 were found to be positive. About $76 \%$ were from 2 to 4 months old puppies. From 92 CPV-2 positive puppies, 28 had been vaccinated and in 11 the HA result could be due to the detection of vaccine virus. Using the polymerase chain reaction, it was possible to confirm the infection by wild virus in 9 vaccinated puppies. By our results risk factors like sex or breed does not seem to interfer on the development of parvovirus enteritis. No seasonal distribution of canine parvovirus was found, and CPV-2 could be detected throughout the year for a five-year period.
\end{abstract}

Keywords. Canine parvovirus; gastroenteritis; Rio de Janeiro.

\section{Introdução}

Até o início da década de 1980, a enterite contagiosa era raramentè observada em cães. Desde que o parvovirus canino (CPV-2) surgiu em 1978 como um novo patógeno de cães, tem sido considerado o agente mais importante de enterite hemorrágica em filhotes entre seis semanas e seis meses de idade (Appel e Parrish, 1987).

Os primeiros sinais clínicos da infecção pelo CPV-2 são inespecíficos e incluem anorexia, depressão, letargia e febre. Vômito e diarréia, geralmente hemorrágica, ocorrem 24 a 48 horas após o sinais prodrômicos. (Macartney et al., 1984; Macintire e Smith-Carr, 1997).
Como os sinais clínicos da gastrenterite podem ser confundidos com os causados por outros agentes, o diagnóstico laboratorial torna-se importante. Este diagnóstico baseia-se principalmente na detecção e/ou isolamento do vírus a partir de amostras fecais obtidas dos casos agudos da infecção. Nesta fase, a quantidade de vírus eliminada pelo animal doente pode alcançar até $10^{\circ} \mathrm{TCID}{ }_{50} / g$ de fezes (Appel e Parrish, 1987).

Um estudo conduzido em São Paulo por Mehnert et al. (1996), a fim de identificar os vírus que causam diarréia hemorrágica em cães, mostrou que o parvovírus canino foi o responsável pelo maior número de casos. Em um estudo preliminar, realizado em Niterói no período de 1995 a 1997, a infecção pelo

\footnotetext{
* Apoio financeiro: CNPq, FAPERJ.

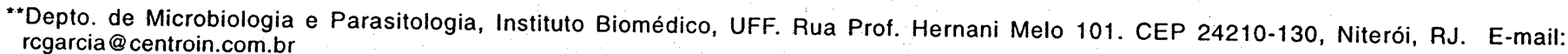

***Depto. de Virologia - IOC/ FIOCRUZ.

***Bolsista de Apoio Técnico - FAPERJ - Depto. de Microbiologia e Parasitologia, UFF

*****Bolsistas 'do PIBIC/CNPq - UFF.

*****Depto. de Clinica Médica de Pequenos Animais, Policlinica Veterinária,UFF.
} 
parvovírus canino pôde ser diagnosticada em aproximadamente $50 \%$ dos casos de gastrenterite (Cubel Garcia et al., 2000).

Este trabalho tem como objetivo realizar o diagnóstico laboratorial dos casos de gastrenterite em filhotes causados pelo parvovírus canino, relacionando os achados clínicos e outros fatores que contribuem para a compreensão da epidemiologia da doença, como idade, raça, sexo e sazonalidade.

\section{Material e métodos}

\section{Amostras}

Duzentas e oito amostras fecais de cães até seis meses de idade, com gastrenterite, no período de abril de 1995 a novembro de 2000, foram obtidas em diferentes locais: 125 da Policlínica Veterinária da UFF e 27 de uma clínica particular, ambas localizadas em Niterói. Trinta e sete amostras foram provenientes de clínicas na cidade do Rio de Janeiro. Outras 12 amostras foram coletadas em Teresópolis, seis em Itaipava e uma em Nova Iguaçu. Cada amostra era acompanhada de uma ficha contendo dados de identificação do animal, data da coleta da amostra, sinais clínicos e histórico das vacinas que o animal recebera.

\section{Diagnóstico laboratorial}

Inicialmente, a partir das amostras fecais, foram preparadas suspensões a $10 \%$ em solução salina balanceada de Hank's (Carmichael et al. 1980). A seguir, estas suspensões foram testadas para a presença de CPV-2 pela reação de hemaglutinação (HA) com hemácias de suíno ou macaco rhesus. Amostras com títulos $\leq 8$ eram consideradas negativas, aquelas com títulos $\geq 16$ pelo teste de HA foram confirmadas como positivas pela reação de inibição da hemaglutinação $(\mathrm{HI})$, utilizando um soro imune anti-CPV-2 (Santos et al.; 1997; Cubel Garcia et al., 2000).

Para o isolamento viral, 12 suspensões fecais com títulos hemaglutinantes variando de 16 a 8192 , foram inoculadas em culturas de células de rim canino Madin Darby (MDCK). Após sete dias de incubação a $37^{\circ} \mathrm{C}$, os sobrenadantes das culturas foram testados para a presença de CPV-2 pela reação de HA (Truyen e Parrish, 1992; Xavier et al., 2000).

Após extração do genoma viral a partir das suspensões fecais a $10 \%$ (Alfieri, 2000), a reação em cadeia pela polimerase (PCR) foi realizada utilizando-se pares de primers que distinguem os tipos antigos (CPV tipo 2) dos novos isolados de parvovírus canino (CPV-2a/2b) (Senda et al., 1995; Pereira et al., 2000).

\section{Resultados}

Amostras fecais de 110 machos e 98 fêmeas foram testadas para a presença de CPV-2 pelos testes de HAVHI, e 92 (52 machos e 40 fêmeas) destas 208 amostras foram positivas. A maioria das amostras positivas eram de animais com 2 (32 amostras), 3 (29) e 4 (12) dias de doença, segundo informação dos proprietários. Conforme mostrado na Tabela 1, 158 das 208 amostras eram de animais com dois a quatro meses de idade, e 72 destas foram positivas. Noventa e três das
208 amostras testadas eram de animais sem raça definida (SRD), e $52 \%$ foram positivas. As outras 117 amostras foram obtidas de animais de raça pura (Tabela 1). Setenta e sete de $90(86 \%)$ animais positivos para CPV-2 apresentaram os sinais clínicos comuns da parvovirose canina: anorexia, apatia, vômito e diarréia (Figura 1), e em 70 destes animais a diarréia era hemorrágica. Temperatura $\geq 39,5^{\circ} \mathrm{C}$ foi observada em somente 18 animais. No período estudado, casos de gastrenterite ocorreram em todos os meses do ano e o CPV2 pode ser detectado em aproximadamente $50 \%$ dos casos (Figura 2).

Tabela 1: Distribuição do número total de casos de gastrenterite e do número total de casos positivos para parvovírus canino em relação ao sexo, idade e raça dos cães examinados no estado do Rio de Janeiro, de 1995 a 2000.

\begin{tabular}{lcc}
\hline & $\begin{array}{c}\mathrm{n}^{\circ} \text { de casos } \\
\text { testados }\end{array}$ & $\begin{array}{c}\mathrm{n}^{\circ} \text { de casos } \\
\text { positivos }\end{array}$ \\
\hline Sexo & & \\
Fêmea & 98 & \\
Macho & 110 & 40 \\
& & 52 \\
Idade (meses) & & \\
$<1$ & 2 & \\
1 & 8 & 2 \\
2 & 57 & 2 \\
3 & 52 & 26 \\
4 & 49 & 25 \\
5 & 16 & 21 \\
6 & 24 & 4 \\
& & 12 \\
Raça & & \\
Sem raça definida (SRD) & 93 & \\
Pastor alemão & 24 & 48 \\
Poodle & 16 & 6 \\
Fila & 12 & 8 \\
Husky siberiano & 8 & 5 \\
Cocker spaniel & 8 & 4 \\
Doberman & 7 & 3 \\
Rottweiler & 6 & 2 \\
Outros * & 34 & 13 \\
\hline
\end{tabular}

* Outros: Dogue Alemão (5), Daschund (4), Labrador (4), Pinscher (4), Boxer (3), Yorkshire (3), Akita (1), Basenjei (1), Beagle (1), Collie (1), Dálmata (1), Pequinês (1), Setter (1), Sharpei (1), Terrier (1) e Weimaraner (1).

Dos 92 animais positivos para CPV-2, 56 não tinham sido vacinados, e para outros oito este dado não era disponível. Entre os 28 animais vacinados, 19 receberam uma dose de vacina, seis receberam duas doses e somente três animais receberam as três doses. Para 13 destes animais vacinados, o intervalo entre a vacinação e o início da doença foi maior que 15 dias, enquanto para seis animais este intervalo foi de 5-11 dias, e para cinco foi de 1-2 dias (Tabela 2). Para quatro animais, este dado não estava disponivel. Pode-se observar também que, para quatro animais vacinados (casos 1 a 4), o intervalo entre a vacinação e coleta das amostras foi de dois dias, para cinco animais (casos 5 a 9) foi de 3-9 dias, e para outros dois (casos 10 e 11) de 11-12 dias. As 11 

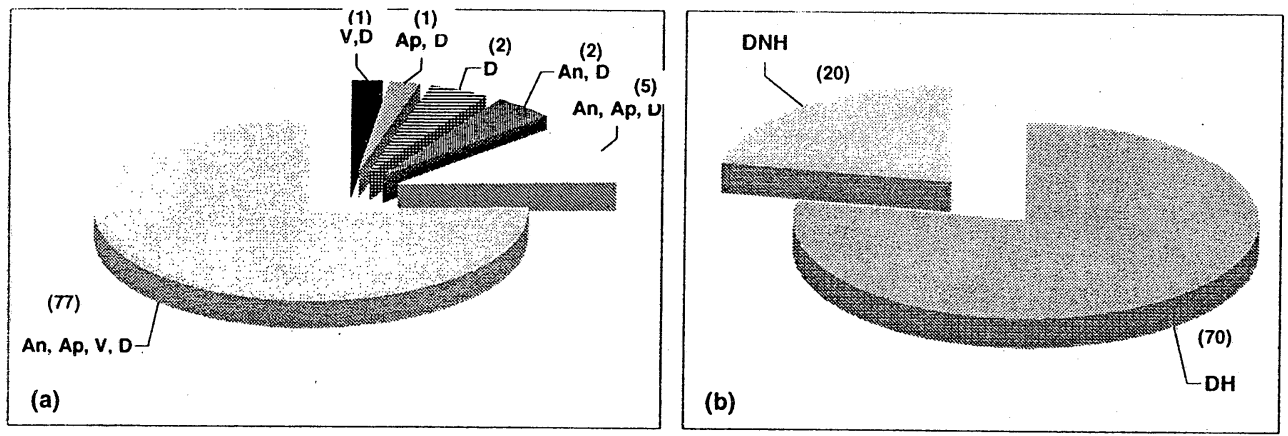

Figura 1: Sinais clinicos apresentados por 90 animais positivos para parvovírus canino.

(a) $\mathrm{An}=$ anorexia, $\mathrm{Ap}=$ apatia, $\mathrm{V}=$ vômito, $\mathrm{D}=$ diarréia.

(b) $\mathrm{DH}=$ diarréia hemorrágica, $\mathrm{DNH}=$ diarréia não hemorrágica.
Tabela 2: Deteç̧ão de parvovírus canino em animais vacinados pelo teste de hemaglutinação, no período de 1995 a 2000 no Rio de Janeiro.

\begin{tabular}{ccc}
\hline Caso $n^{0}$ & \multicolumn{2}{c}{$N^{0}$ de dias entre a vacinação e } \\
\cline { 2 - 3 } & \multicolumn{2}{c}{$\begin{array}{c}\text { coleta das } \\
\text { amosio da doença }\end{array}$} \\
\hline 1 & 1 & 2 \\
2 & 1 & 2 \\
3 & 1 & 2 \\
4 & 1 & 2 \\
5 & 2 & 3 \\
6 & 5 & 6 \\
7 & 5 & 7 \\
8 & 7 & 8 \\
9 & 7 & 9 \\
10 & 8 & 11 \\
11 & 11 & 12 \\
\hline
\end{tabular}

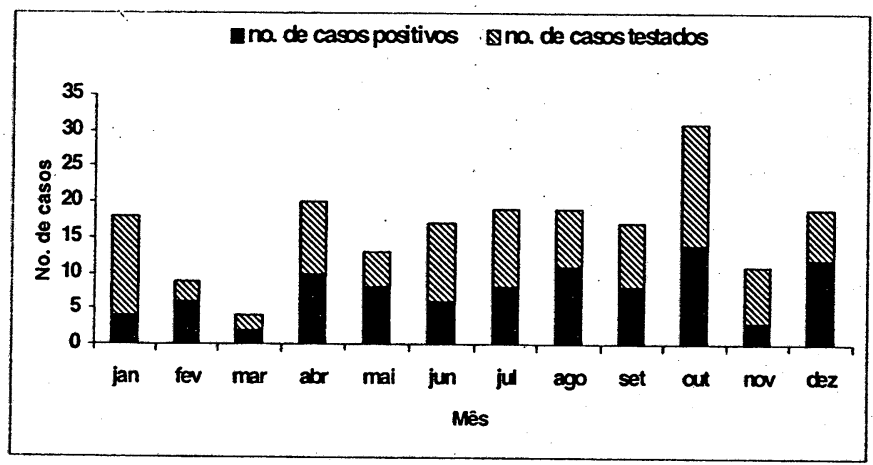

Figura 2: Distribuição do número de casos positivos em relação ao numero de casos testados para parvovírus canino no Rio de Janeiro de 1995 a 2000.

amostras fecais de cães vacinados, positivas para CPV-2 por HAVHI, foram submetidas à PCR, e o genoma viral pôde ser amplificado em nove amostras com par de primer específico para os tipos novos (CPV-2a/2b) de parvovírus canino.
Tabela 3: Títulos hemaglutinantes (HA) das suspensões fecais a $10 \%$ e das amostras isoladas em cultura de células (CC).

\begin{tabular}{ccc}
\hline \multirow{2}{*}{$\begin{array}{c}\text { Título de HA da } \\
\text { suspensão fecal a 10\% }\end{array}$} & \multicolumn{2}{c}{ Título de HA do isolamento em CC } \\
\cline { 2 - 3 } & Inóculo * & Sobrenadante \\
\hline 16 & $\mathrm{~b}^{\star \star}$ & 8 \\
16 & $\mathrm{~b}$ & 32 \\
128 & 8 & 64 \\
256 & 8 & 256 \\
256 & 8 & 256 \\
512 & $<\mathrm{b}$ & 8 \\
512 & $<\mathrm{b}$ & 128 \\
1024 & $<\mathrm{b}$ & 8 \\
2048 & 16 & 1024 \\
2048 & 4 & 32 \\
8192 & 4 & 32 \\
8192 & 32 & 256 \\
\hline
\end{tabular}

* Inóculo: suspensão fecal a $10 \%$ diluída em meio de cultivo celular para inoculação em cultura de célula.

** b: bruto

Em relação ao isolamento do parvovírus em MDCK, um aumento no título hemaglutinante do sobrenadante da cultura de células pode ser observado (Tabela 3), mesmo quando suspensões fecais com títulos hemaglutinantes iguais a 16 foram inoculadas. Estas suspensões fecais, quando testadas por HI, para confirmação do resultado do HA, eram negativas.

\section{Discussão}

No presente estudo foi possivel demonstrar por HA/HI, a infecção pelo parvovírus canino em $44 \%$ dos casos de gastrenterite em animais até seis meses de idade, no periodo de 1995 a 2000 no Rio de Janeiro. Conforme também observado em outros trabalhos (Houston et al. 1996, Homem et al. 1999), a infecção por CPV-2 é mais comum em animais de dois a quatro meses de idade. Nesta faixa etária, os animais não completaram o protocolo de vacinação ou ainda não foram vacinados.

Entre os animais positivos para CPV-2, 28 tinham recebido uma, duas ou três doses de vacina contra parvovirose. Ape- 
sar de não ser possível diferenciar entre virus selvagem e vacinal pelo teste de hemaglutinação, sabe-se que o virus vacinal só pode ser detectado nas fezes, por este teste, no período de três a nove dias após inoculação oral (Carmichael et al., 1981). Portanto, para 13 destes animais, o resultado positivo no HA não significa detecção de vírus vacinal, pois o intervalo entre a vacinação e início da doença foi maior que 15 dias. Outros cinco animais receberam a vacina provavelmente no período de incubação da doença (1-2 dias), e para somente um destes (caso no 5) a amostra foi coletada no período em que é possivel detectar vírus vacinal nas fezes por HA. Para cinco animais (casos 6 a 9), o resultado positivo no $\mathrm{HA}$ pode ter sido devido à detecção de vírus vacinal, pois as amostras fecais foram coletadas no período de seis a nove dias pós vacinação.

Vários trabalhos na literatura mostram que desde que emergiu em 1978 como um novo patógeno de cães, as amostras de parvovírus canino podem ser diferenciadas em CPV tipo 2, $2 a$ ou $2 b$, pela reação com anticorpos monoclonais, diferenças no mapa de restrição (Parrish, 1994), e mais recentemente, pela reação em cadeia pela polimerase (PCR) (Senda et al. 1995, Pereira, 2000). A fim de esclarecer se o resultado positivo do teste de HA nos 11 animais vacinados foi devido à detecção de vírus selvagem ou vacinal, as amostras foram testadas pela PCR utilizando-se pares de primers que diferenciam o tipo antigo (CPV-2) dos tipos novos (CPV-2a/ b) de parvovirus canino. Como as vacinas administradas nestes animais eram constituídas de CPV-2, tipo antigo, pôdese esclarecer a infecção pelo vírus selvagem (CPV-2a/2b) em nove dos 11 casos.

Embora alguns trabalhos mostrem que algumas raças são mais ou menos suscetiveis ao desenvolvimento da parvovirose (Glickman et al., 1985, Houston et al. 1996), isto não pôde ser evidenciado neste estudo, pois 91 das 208 amostras eram de animais sem raça definida, e as demais 117 foram distribuídas entre 25 raças diferentes. Em relação ao sexo, também nenhuma diferença foi observada, já que machos e fê- meas foram positivos quase que na mesma proporção. Em estudos realizados no Canadá e Estados Unidos (Hammond et al. 1983, Houston et al. 1996), um maior número de casos de enterite hemorrágica foi observado nos meses mais quentes do ano (julho a setembro). Dados obtidos da Policlínica Veterinária da UFF, no período de 1995 a 2000, mostram que casos de gastrenterite ocorrem todos os meses do ano e correspondem a $10 \%$ dos atendimentos (Cubel Garcia et al., 2000). Neste trabalho, o CPV-2 pôde ser detectado em todos os meses do ano, sem apresentar uma sazonalidade definida.

Desde os primeiros relatos da ocorrência de parvovirose canina no Brasil nos anos de 1979-80 em São Paulo (Angelo et al. 1980, Hagiwara et al. 1980), o CPV-2 ainda é considerado o agente mais importante de gastrenterite em filhotes apesar da vacinação. Mehnert et al. (1996), ao estudarem os agentes responsáveis por enterite hemorrágica em cães em 1115 amostras fecais, identificaram o parvovírus canino como sendo o responsável por aproximadamente $40 \%$ dos casos. Homem et al. (1999), ao analisarem 20 amostras de casos de gastrenterite por microscopia eletrônica, observaram partículas semelhantes a parvovírus em seis $(24 \%)$ casos. Os resultados deste trabalho mostram que o parvovírus canino é ainda uma importante causa de gastrenterite em filhotes no Rio de Janeiro.

O isolamento do vírus em cultura de células permitirá o diagnóstico de CPV-2 em amostras consideradas negativas pelo teste de HA (títulos hemaglutinantes < 64). A reação de polimerização em cadeia possibilitará a caracterização genômica das amostras de parvovírus em CPV-2, $2 \mathrm{a}$ ou $2 \mathrm{~b}$, de modo a se conhecer as variantes de CPV-2 que circulam no Rio de Janeiro, a fim de compará-las com as amostras que circulam em outros estados do nosso país, ou mesmo em outros países. Portanto, o diagnóstico laboratorial dos casos de gastrenterite por CPV-2 é importante não só para se estabelecer a etiologia da doença, mas também para se realizar um estudo molecular das amostras que estão em circulação.

\section{Agradecimentos}

Agradecemos à Policlínica Veterinária da UFF e às clínicas veterinárias que nos enviaram amostras fecais de casos de gastrenterite, possibilitando a realização deste estudo.

\section{Referências}

ALFIERI, A. F. Caracterização dos genótipos $G$ e $P$ de rotavírus grupo A de origem animal (bovina e suína) e de origem humana pela reação da polimerase em cadeia. 1999. $134 \mathrm{f}$. Tese (Doutorado) Faculdade de Medicina Veterinária e Zootecnia - Universidade de São Paulo.

ANGELO, M. J. O.; HAGIWARA, M.;K.; JULY, J. R.; CARVALHO, R. P. S.; BACCARO, M. R. Isolamento de parvovírus canino no Brasil. Rev. Fac. Vet. Zootec. da Universidade de São Paulo, v. 25, p. 123-134, 1980.

APPEL, M.; PARRISH, C. R. Canine parvovirus type 2. In: Appel, M.S. Virus infections of carnivores. Amsterdam, Elsevier Science Publishers, 1987. p. 69-92.

CARMICHAEL, L. E.; JOUBERT, J. C.; POLLOCK, R. V. H. Hemagglutination by canine parvovirus: serologic studies and diagnostic applications. Am. J. Vet. Res., v. 41, n. 5, p. 784-791, 1980.
CARMICHAEL, L. E.; JOUBERT, J. C.; POLLOCK, R. V. H. A modified live canine parvovirus strain with novel plaque caracteristics. I. Viral attenuation and dog response. Cornell Vet., v. 71, p. 408-421, 1981.

CUBEL GARCIA, R. C. N.; PINTO, A.; COSTA, A.; MACIEL, B.; OLIVEIRA, L.; NASCIMENTO, J.; SANTOS, A.; WIUI, L; LABARTHE, N. Canine parvovirus infection in puppies with gastroenteritis in Niterói, Rio de Janeiro, from 1995 to 1997. Brazilian Journal of Vererinary Research and Animal Science[Periodico on line] v. 37, n. 2, 2000. Disponivel em URL: http://www.scielo.br/bjvras.

GLICKMAN, L. T.; DOMANSKI, L. M.; PATRONCK, G. J.; VISINTAINER, F. Breed-related risk factors for canine parvovirus enteritis. J. Am. Vet. Med. Assoc., v. 187, n. 6, p. 589-594, 1985.

HAGIWARA, M. K.; JULY, J. R.; BACCARO, M. R.; ANGELO, M. J. O. Enterite hemorrágica em cães associada à infecção por um parvovírus. Arq. Inst. Biol., v. 47, n. 1/2, p. 47-9, 1980.

HAMMOND, M. M.; TIMONEY, P. J. An electron microscopic study of viruses associated with canine gastroenteritis. Cornell Vet., v. 73, p.
$82-97,1983$. 
HOMEM, V. S. F.; MENDES, Y. G.; LINHARES, A. C. Gastrenterite canina - agentes virais nas fezes de cães diarréicos e não-diarréicos. Arq. Bras. Med. Vet. Zootec., v. 51, n. 6, p. 531-536, 1999.

HOUSTON, D. M.; RIBBLE, C. S.; HEAD, L. L. Risk factors associated with parvovirus enteritis in dogs: 283 cases (1982-1991). J. Am. Vet. Med. Assoc, v. 208, n. 4, p. 542-546, 1996.

MACARTNEY, L.; MCCANDLISH, I. A. P.; THOMPSON, H.; CORNWELL, H. J. C. Canine parvovirus enteritis 2: Pathogenesis. Vet. Rec., v. 115, p. 453-460, 1984.

MACINTIRE, D. K.; SMITH-CARR, S. Canine Parvovirus. Part II: Clinical signs, diagnosis and treatment. Comp. Cont. Educ. Small Animal, v. 19, n. 3, p. 291-302, 1997.

MEHNERT,D. U.;MONEZI, T. A.;PRADO, M. A.; HÁRSI, C.M.; CAVALIERO, M. J.; QUEIROZ, A. P. S.; MÜLLER, N. G.; ANGELO, M. J. O. Canine gastroenteritis in Brazil: Preliminary results of a viral etiological study. In: ENCONTRO NACIONAL DE VIROLOGIA, 11. São Lourenço, 1996. Anais,... São Lourenço, Sociedade Brasileira de Virologia, p. 43.

PARRISH, C. R. The emergence and evolution of canine parvovirus an example of recent host range mutation. Sem. Virol., v. 5, p. 121132,1994
PEREIRA, C. A. D.; MONEZI, T. A.; MEHNERT, D. U.; D'ANGELO, M.; DURIGON, E. L. Molecular characterization of canine parvovirus in Brazil by polymerase chain reaction (PCR). Vet. Micriobiol., v. 75, n. 2, p. 127-133, 2000.

SENDA, M.; PARRISH, C. R.; HARASAWA, R.; GAMOH, K.:MURMATSU, M.; HIRAYAMA, N.; ITOH, O. Detection by PCR of wild-type canine parvovirus which contaminates dog vaccines. J. Clin. Microbiol., v. 3, n. 1, p. 110-113, 1995.

SANTOS, P.; PINTO, A. M. V.; CUBEL GARCIA, R. C. N.; LABARTHE, N.V.; OLIVEIRA, L. H. S. Padronização de reagentes e métodos utilizados na técnica de hemaglutinação para o diagnóstico laboratorial da parvovirose canina. R. bras. Ci. Vet., v. 4, n. 3, p. 111-115, 1997.

TRUYEN, U.; PARRISH, C. R. Canine and feline host range of canine parvovirus and feline panleukopenia virus: distinct host cell tropisms of each virus in vitroand in vivo. J. Virol., n. 66, p. 5399-5408, 1992.

XAVIER, M.P. T.; CASTRO, T.; MERTENS, R.; LABARTHE, N.; LEITE, J. P.; CUBEL GARCIA, R. C. N. Diagnosis of canine parvovirus by virus isolation in cell culture. Virus Reviews \& Research, v. 5., n. 2., p. 159, 2000. 